\title{
The Necessity of Preserving the Research System in Emergency Eras
}

\author{
Ahmad Shamabadi, MD ${ }^{1,2}$; Shahin Akhondzadeh, $\mathrm{PhD}^{1 *}$ \\ ${ }^{1}$ Psychiatric Research Center, Roozbeh Psychiatric Hospital, Tehran University of Medical Sciences, Tehran, Iran \\ ${ }^{2}$ School of Medicine, Tehran University of Medical Sciences, Tehran, Iran
}

\section{Dear Editor,}

The emergency of the all-society-inclusive coronavirus outbreak has cast a shadow over research and scientific journals. In the pandemic era, the time from submission to publication of related articles has exceptionally decreased by a remarkable reduction in peer-review process time. ${ }^{1}$ Shortening the time between receipt and acceptance to six days ${ }^{2}$ is helpful but should not compromise the quality of studies or the quality of studies a journal publishes, as was the case with reputable medical journals. ${ }^{3}$ Undermining the long-established existing rules and regulations in research and journals would have unfathomable consequences. Providing ineffective services (e.g., manuscripts on treatment of a disorder during the pandemic without examining patients and only by repeating results previously published) will confuse researchers in subsequent epidemics. Publication of articles has external effects, which publishing journals editors should consider.

A trial aimed at demonstrating a drug s effectiveness should have a high-quality methodology and fully explain the patient demographics due to the broad spectrum of COVID-19 symptoms severity. Even in a high-quality study, avoiding jumping to conclusions is necessary. A statistically significant result is not necessarily clinically significant - as a consequence of effect size and method bias. ${ }^{4}$ When methodologies are not heeded, conducting a high-quality study with a large sample size calls conclusion of all previous studies into question, as happened with hydroxychloroquine for COVID-19. ${ }^{5}$

During the ongoing coronavirus pandemic affecting all the society, people are directly following SARS-CoV-2related studies from scientific journals. Public awareness is helpful, but people may not have a completely accurate understanding of scientific articles. Addressing people directly through the media prompted requests and created illicit and black markets for drugs with inconclusive effects and raised expectations of possible vaccines. In addition, retraction of articles in dependable medical journals raised public concerns about journals and articles' credibility. ${ }^{6}$ Another important issue here is that retracted articles are still cited by researchers to support the findings and claims, even in reputable journals.?

The creation of new subtypes of viruses resulting from their biological phenomenon of reassortment indicates that subsequent epidemics are not far-fetched. ${ }^{8}$ The need to preserve the long-established science-centric system in research and journals in the COVID-19 pandemic and subsequent emergency eras is undeniable.

\section{Authors' Contribution}

AS wrote the manuscript. SA edited the manuscript. Both authors approved the final version.

\section{Conflict of Interest Disclosures}

The authors have no conflict of interests.

Ethical Statement

None.

\section{References}

1. Horbach SP. Pandemic publishing: medical journals strongly speed up their publication process for COVID-19. Quant Sci Stud. 2020;1(3):1056-67. doi: 10.1162/qss_a_00076.

2. Palayew A, Norgaard O, Safreed-Harmon K, Andersen TH, Rasmussen LN, Lazarus JV. Pandemic publishing poses a new COVID-19 challenge. Nat Hum Behav. 2020;4(7):6669. doi: 10.1038/s41562-020-0911-0.

3. Zdravkovic M, Berger-Estilita J, Zdravkovic B, Berger D. Scientific quality of COVID-19 and SARS CoV-2 publications in the highest impact medical journals during the early phase of the pandemic: a case control study. PLoS One. 2020;15(11):e0241826. doi: 10.1371/journal. pone.0241826.

4. Wasserstein RL, Lazar NA. The ASA statement on p-values: context, process, and purpose. Am Stat. 2016;70(2):129-33. doi: 10.1080/00031305.2016.1154108

5. Pan H, Peto R, Henao-Restrepo AM, Preziosi MP, Sathiyamoorthy V, Abdool Karim Q, et al. Repurposed antiviral drugs for COVID-19 - interim WHO SOLIDARITY trial results. N Engl J Med. 2021;384(6):497511. doi: 10.1056/NEJMoa2023184.

6. Rabin RC. The Pandemic Claims New Victims: Prestigious Medical Journals. The New York Times; 2020. Available from: $\quad$ https://bioethics.pitt.edu/sites/default/files/ 
Pandemic_Claims_Victims.pdf. Accessed December 2020.

7. Piller C. Disgraced COVID-19 studies are still routinely cited. Science. 2021;371(6527):331-2. doi: 10.1126/ science.371.6527.331.
8. Vijaykrishna D, Mukerji R, Smith GJ. RNA virus reassortment: an evolutionary mechanism for host jumps and immune evasion. PLoS Pathog. 2015;11(7):e1004902. doi: 10.1371/journal.ppat.1004902.

Received: February 6, 2021, Accepted: March 13, 2021, ePublished: July 1, 2021

Cite this article as: Shamabadi A, Akhondzadeh S. The necessity of preserving the research system in emergency eras. Arch Iran Med. 2021;24(7):823-584. doi: 10.34172/aim.2021.82

(c) (i) The Author(s). This is an open-access article distributed under the terms of the Creative Commons Attribution License (http://creativecommons.org/ licenses/by/4.0), which permits unrestricted use, distribution, and reproduction in any medium, provided the original work is properly cited. 